\title{
Highlights from this issue
}

doi:10.1136/sextrans-2011-050286

As England waits with bated breath for the government's decision whether to fund Cervarix (the bivalent vaccine currently used in the national vaccination programme) or quadrivalent Gardasil, we publish two papers exploring the impact of genital warts in England. This is a difficult area to study, since patients with genital warts may present in a variety of settings, and be referred between them. In an unlocked article, Desai et a ${ }^{1}$ estimate diagnosed incidence in general practice using a large primary care database, and in genitourinary medicine specialist clinics. With an estimated $1.3 \%$ of cases requiring hospital care, the authors conclude that morbidity costing $£ 16.8 \mathrm{M}$ per year could be largely prevented by a change in vaccine. Readers may be aware that a survey of members of British Association for Sexual Health and HIV Research showed that $61 \%$ with daughters in the relevant age group had actually paid for them to have Gardasil (REF http://www.bashh.org.uk). A second paper by the same QOLIGEN team $^{2}$ estimates the mean impact of genital warts at 6.6 days of healthy life lost per episode, and it is likely that sexual health physicians are more likely to see patients at the upper end of the spectrum. These papers have already generated debate online, and we hope you will join it.

Chlamydia control remains a vexed area of policy and practice. We publish this month an important editorial ${ }^{3}$ which explores the wider mplications of variation in uptake of chlamydia screening. The original paper Riha et a $l^{4}$ showed that those accepting screening had higher levels of risk behaviour than non-screeners. Heijne and Low point out in the editorial that mathematical modelling will have to revisit its assumption of random uptake of screening, while we need to know more about what determines the offer and uptake of testing.

An interesting paper by Berry et al ${ }^{5}$ reports the implementation of universal annual screening for STI in an HIV clinical cohort. This practice has gradually become established, and is subject to a CDC recommendation in the USA. The authors documented an increase in the proportion screened annually from 0.12 to 0.33 between 1999 and 2007, but this was not associated with any increase in the proportion of patients diagnosed with gonorrhoea or chlamydia. Their discussion explores the implications of these findings for efforts to further increase uptake of screening, and suggests that a more targeted approach may be justified.

Tipple et $a l^{6}$ explore the potential of quantitative PCR to enhance our understanding of early syphilis. They suggest that ulcers in primary syphilis may be more infectious among HIV positive individuals, while bacteraemia peaks during the secondary stage. In this same issue, they also present worrying findings about macrolide resistance, ${ }^{7}$ detecting a $23 \mathrm{~S}$ rRNA point mutation conferring macrolide resistance was found in $66.6 \%$ of samples from 18 homosexually active men.

The plight of fishing communities at high risk of HIV is emphasised in new data published by Asiki et al. ${ }^{8}$ Their data from a population based survey in Uganda showed a $28.8 \%$ HIV prevalence. The authors point out that these highly vulnerable populations have not yet received the generalised or focused HIV interventions that they need.

The epidemiology of different serovars of chlamydia is intriguingly explored this month, with Bax et al ${ }^{9}$ reporting likely rectal tissue tropism by the G/Ga serovar, and Templeton et al ${ }^{10}$ reporting serovar $\mathrm{D}$ as most common in a largely asymptomatic population of men who have sex with men in Australia.

For our next edition-a Christmas special-we are planning a nostalgic theme. A young historian has agreed to look through our archive, exploring how syphilis, herpes and HIV have appeared as stigmatised conditions to our readership.
Jackie A Cassell, Editor

This has become suddenly topical with the news that a British man has been sentenced to 14 months imprisonment for 'reckless transmission of an incurable sexually transmitted infection' after his ex-partner was diagnosed with genital herpes. Even the satirical weekly Private Eye-a publication not known for liberal views-thinks that the Crown Prosecution Service 'went back to the dark ages'. More on this next month....

Provenance and peer review Not commissioned; internally peer reviewed.

\section{REFERENCES}

1. Desai S, Wetten S, Woodhall SC, et al. Genital warts and cost of care in England. Sex Transm Infect 2011;87:464-8.

2. Woodhall SC, Jit M, Soldan K, et al. The impact of genital warts: loss of quality of life and cost of treatment in eight sexual health clinics in the UK. Sex Transm Infect 2011;87:458-63.

3. Heijne MJC, Low N. Differential selection processes in opportunistic chlamydia screening. Sex Transm Infect 2011;87:454-5.

4. Riha J, Mercer $\mathrm{CH}$, Soldan $\mathrm{K}$, et al. Who is being tested by the English National Chlamydia Screening Programme? A comparison with national probability survey data. Sex Transm Infect 2011;87:306-11.

5. Berry SA, Ghanem KG, Page KR, et al. Increased gonorrhoea and chlamydia testing did not increase case detection in an HIV clinical cohort 1999-2007. Sex Transm Infect 2011;87:469-75.

6. Tipple C, Hanna MOF, Hill S, et al. Getting the measure of syphilis: qPCR to better understand early infection. Sex Transm Infect 2011;87:479-85.

7. Tipple C, McClure MO, Taylor GP. High prevalence of macrolide resistant Treponema pallidum strains in a London centre. Sex Transm Infect 2011;87:486-8.

8. Asiki G, Mpendo J, Abaasa A, et al. HIV and syphilis prevalence and associated risk factors among fishing communities of Lake Victoria, Uganda. Sex Transm Infect 2011;87:511-5.

9. Bax CJ, Quint KD, Peters RPH, et al. Analyses of multiple-site and concurrent Chlamydia trachomatis serovar infections, and serovar tissue tropism for urogenital versus rectal specimens in male and female patients. Sex Transm Infect 2011;87:503-7.

10. Templeton DJ, Twin J, Jin F, et al. Chlamydia trachomatis serovars in communitybased HIV-positive and HIV-negative men who have sex with men in Sydney, Australia. Sex Transm Infect 2011;87:501-2 